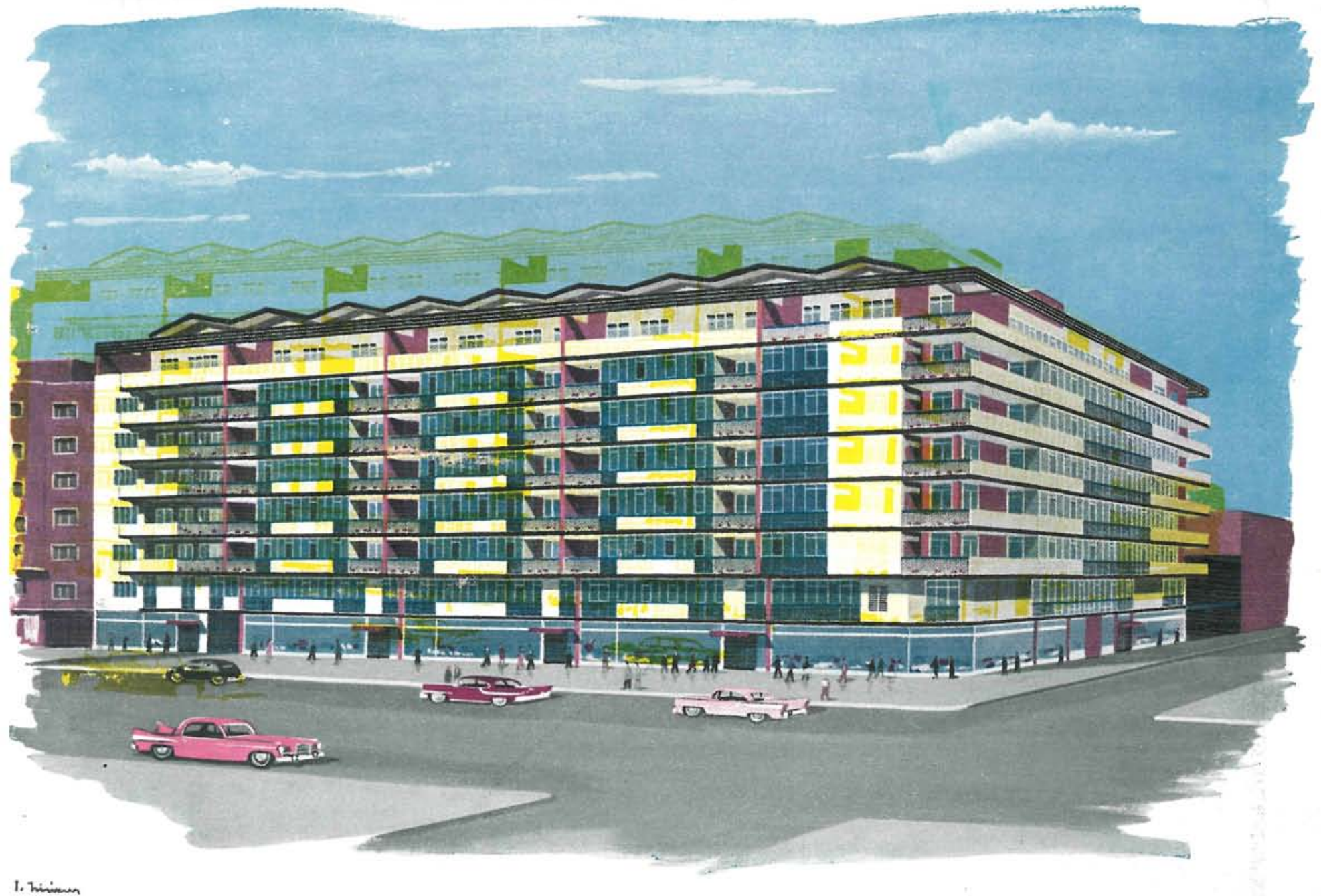

$123 \cdot 60$

\title{
bloque de viviendas, en Madrid
}

M. GARCIA BENITO, arquitecto

\section{edificio luz}

El solar, con fachadas a General Pardiñas y General Oráa en longitudes de $67,89 \mathrm{~m}$ y $30,36 \mathrm{~m}$, exigía buscar una solución de conjunto de todas las edificaciones que iba a albergar. Todas ellas destinadas a viviendas.

Como es natural en estos casos, buscando un máximo aprovechamiento de superficie y volumen permitido por Ordenanzas. No obstante, el aprovechamiento racional de un solar no está precisamente en el macizado de las superficies permitidas.

Esto ha sido el motivo de que al tratar del estudio de conjunto se pensase en proyectar un bloque de planta rectangular, con la profundidad de edificación permitida de $25 \mathrm{~m}$, prescindiendo de parte del solar recayente a General Oráa para establecer una comunicación desde el exterior al patio de manzana a través de una pequeña zona ajardinada por la que se accede al garaje construído dentro de él.

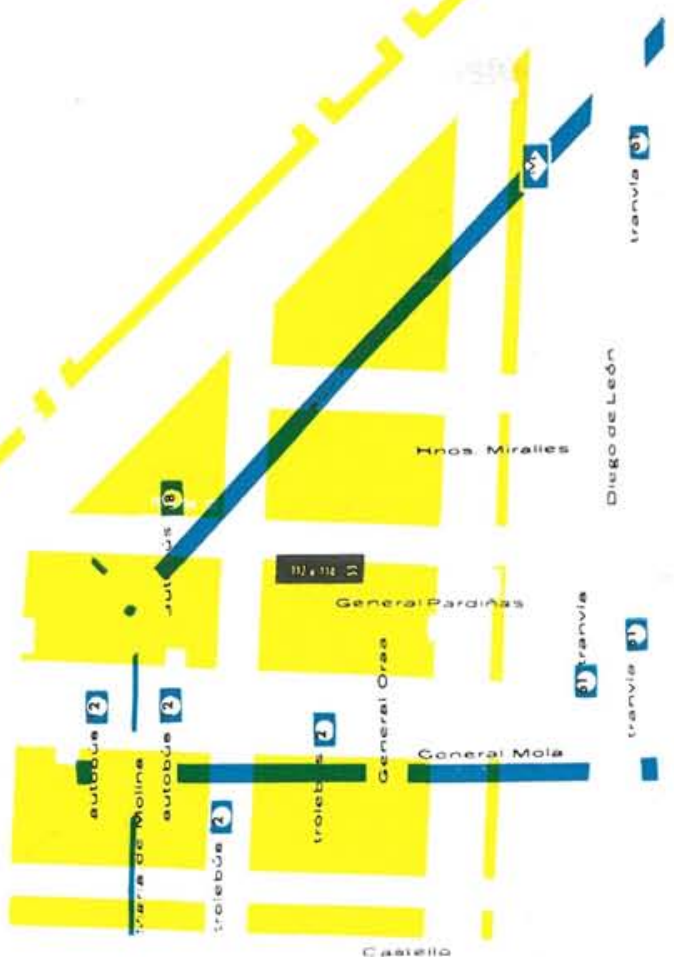




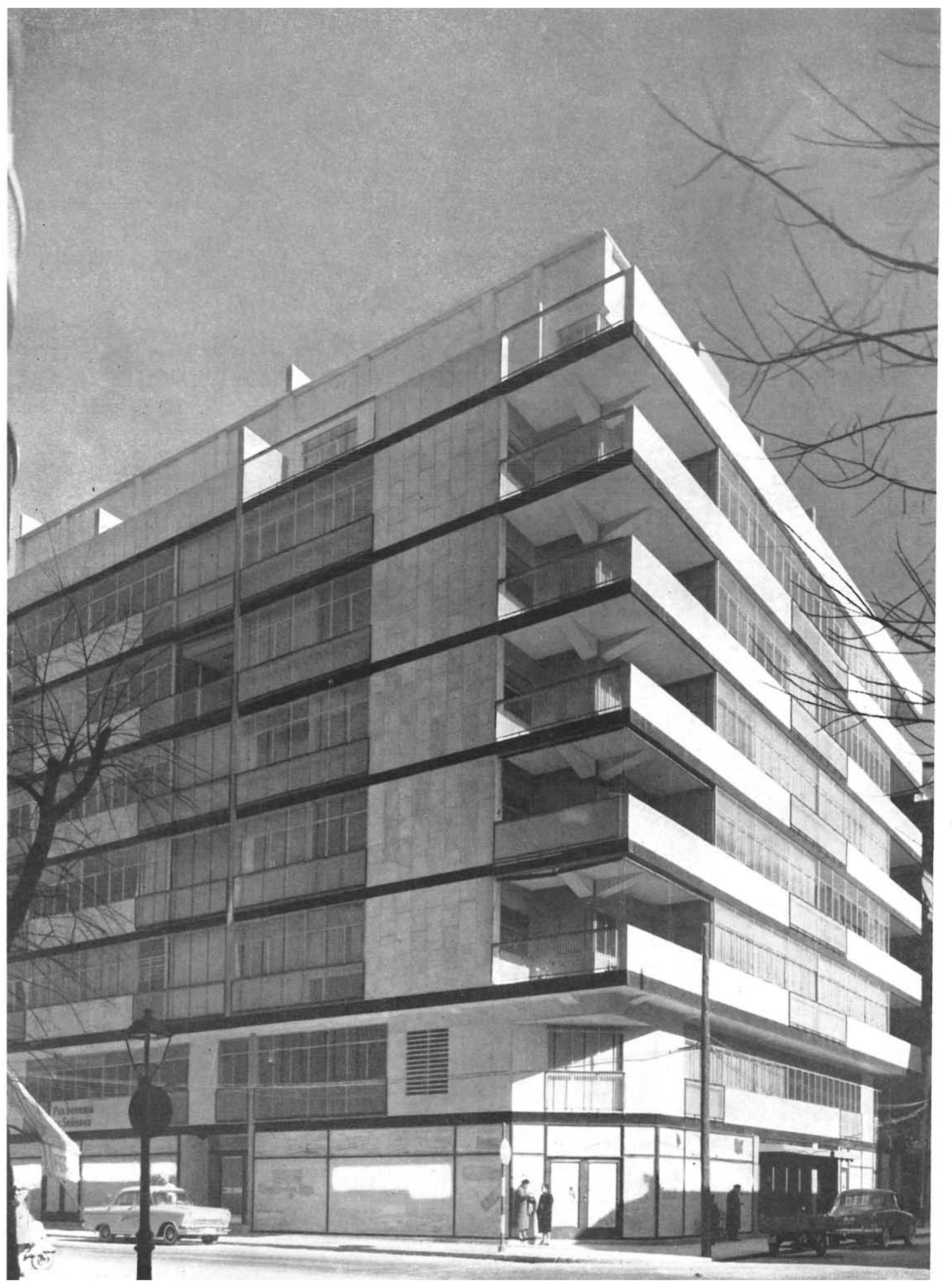



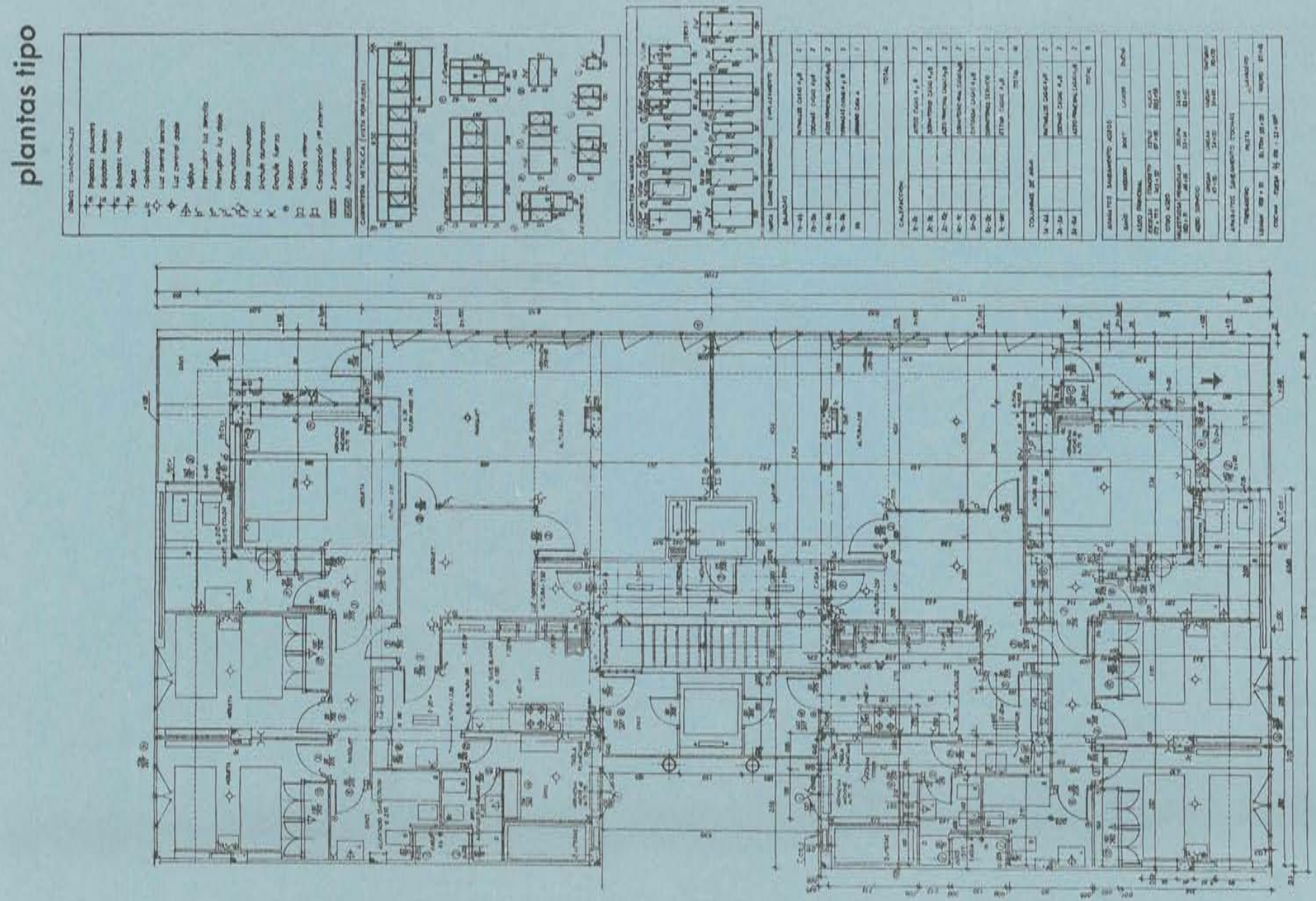

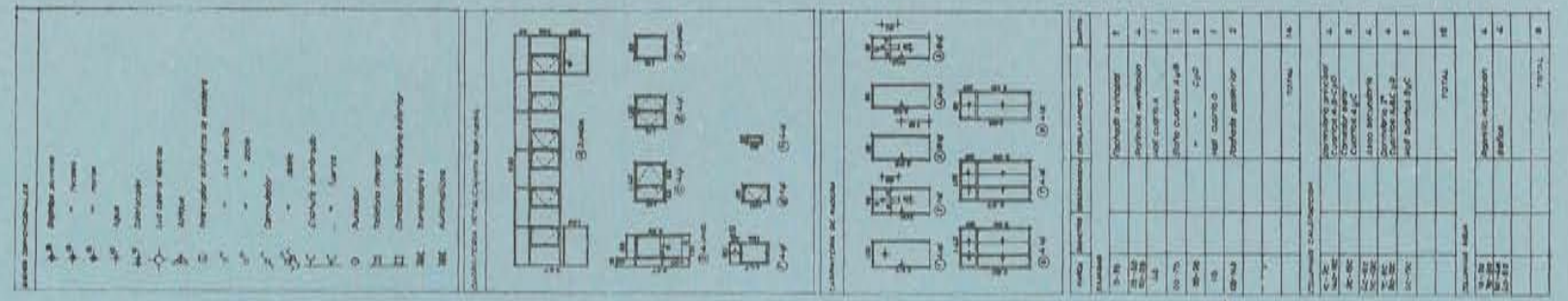

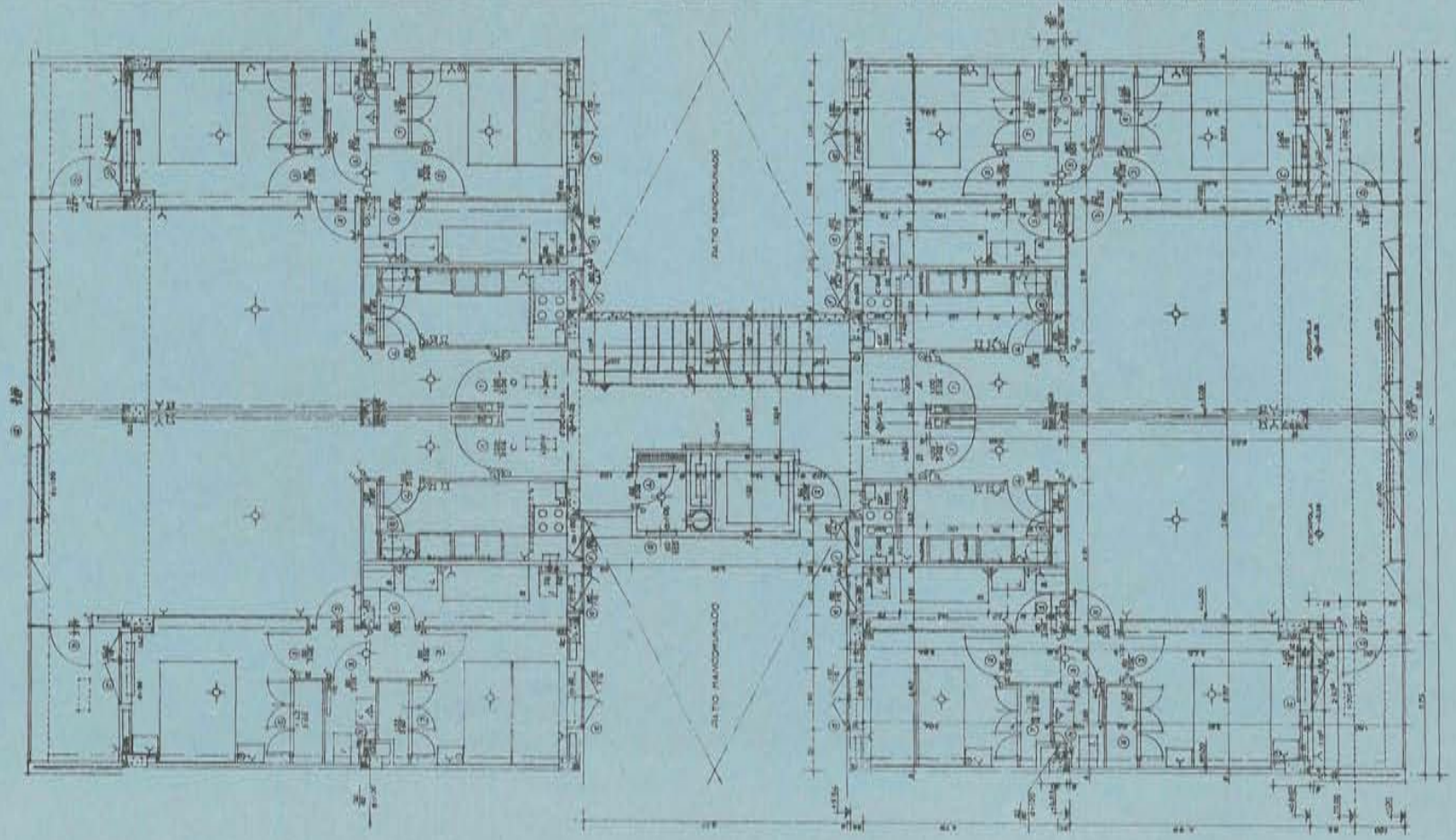



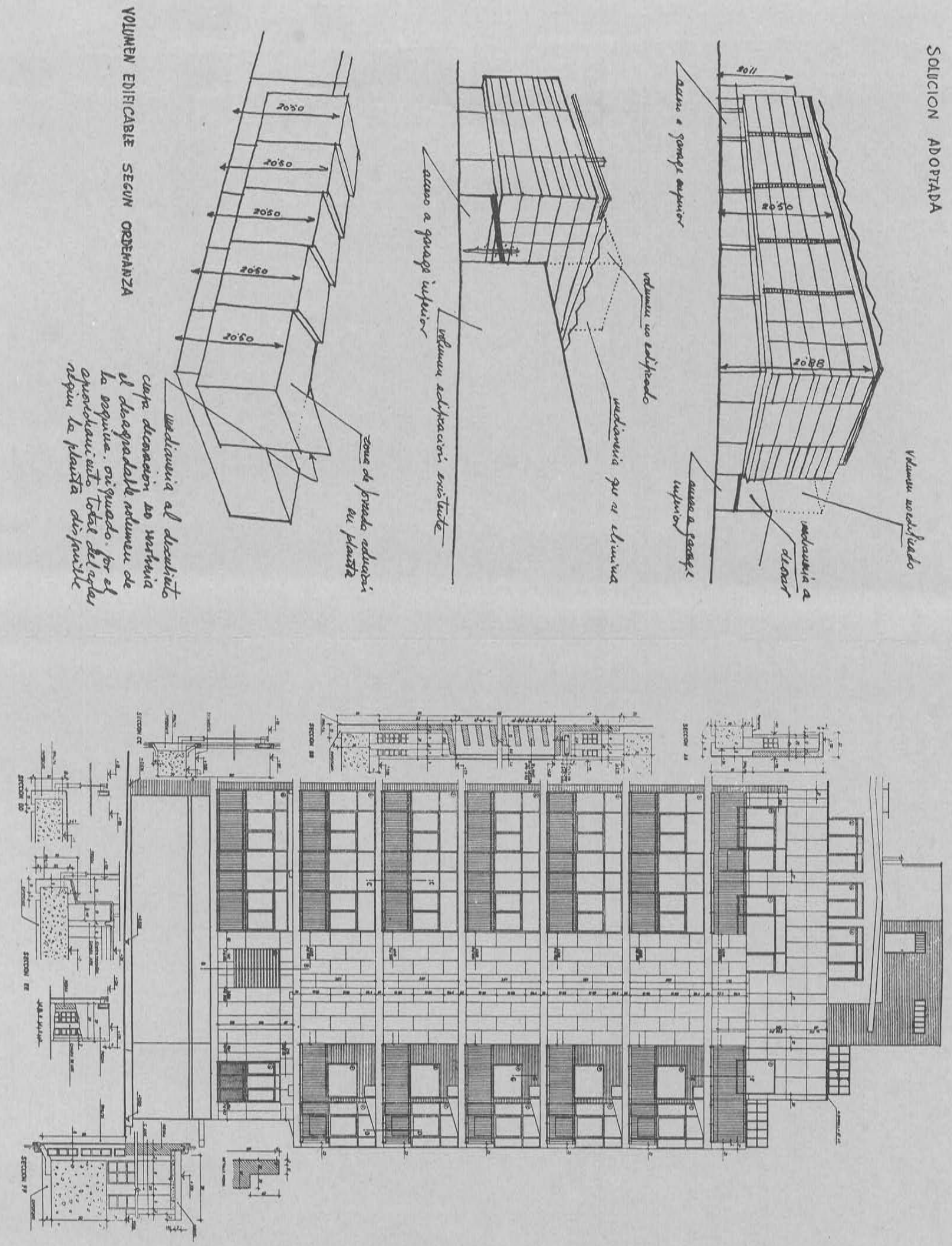

detalle de fachada 

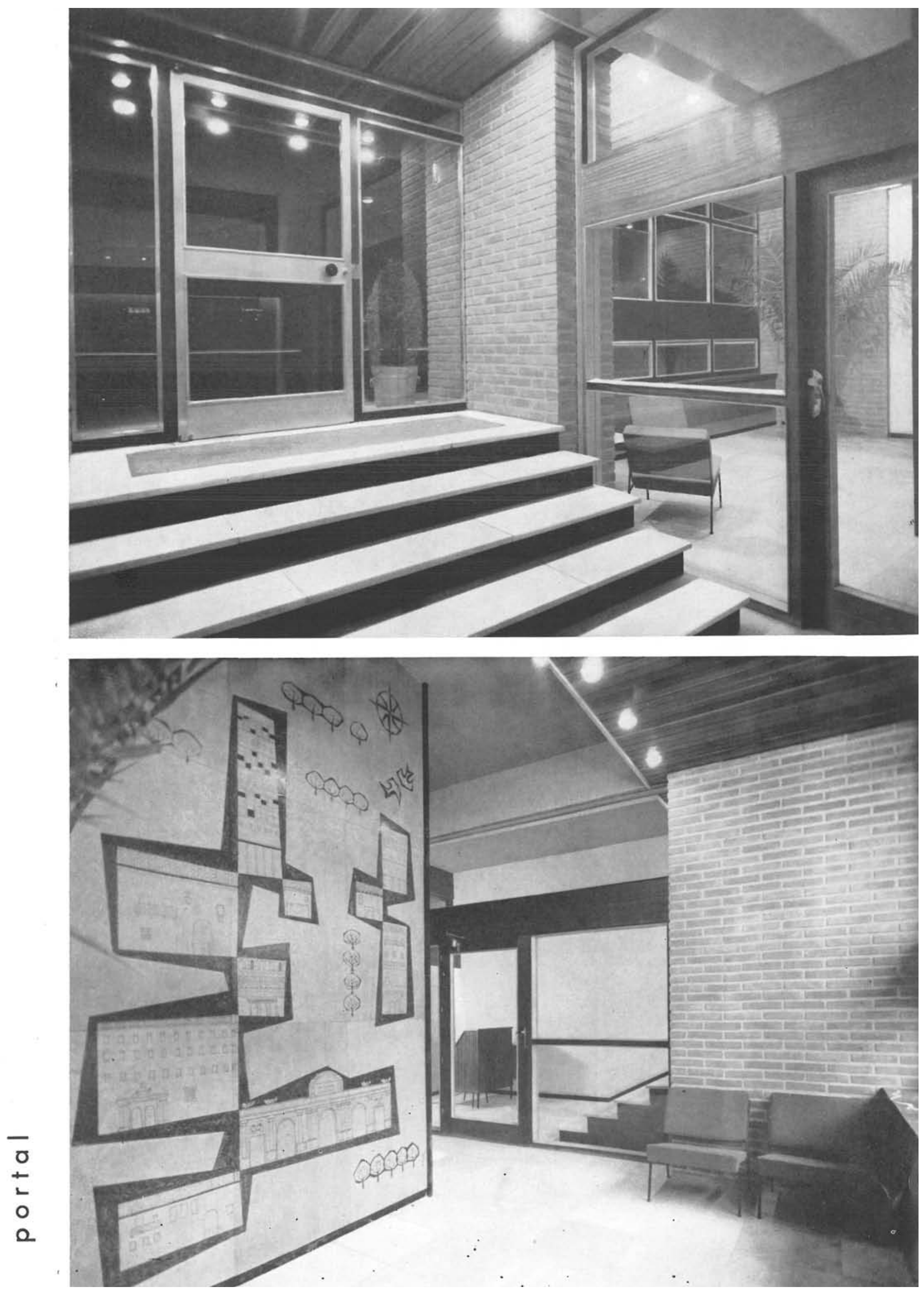


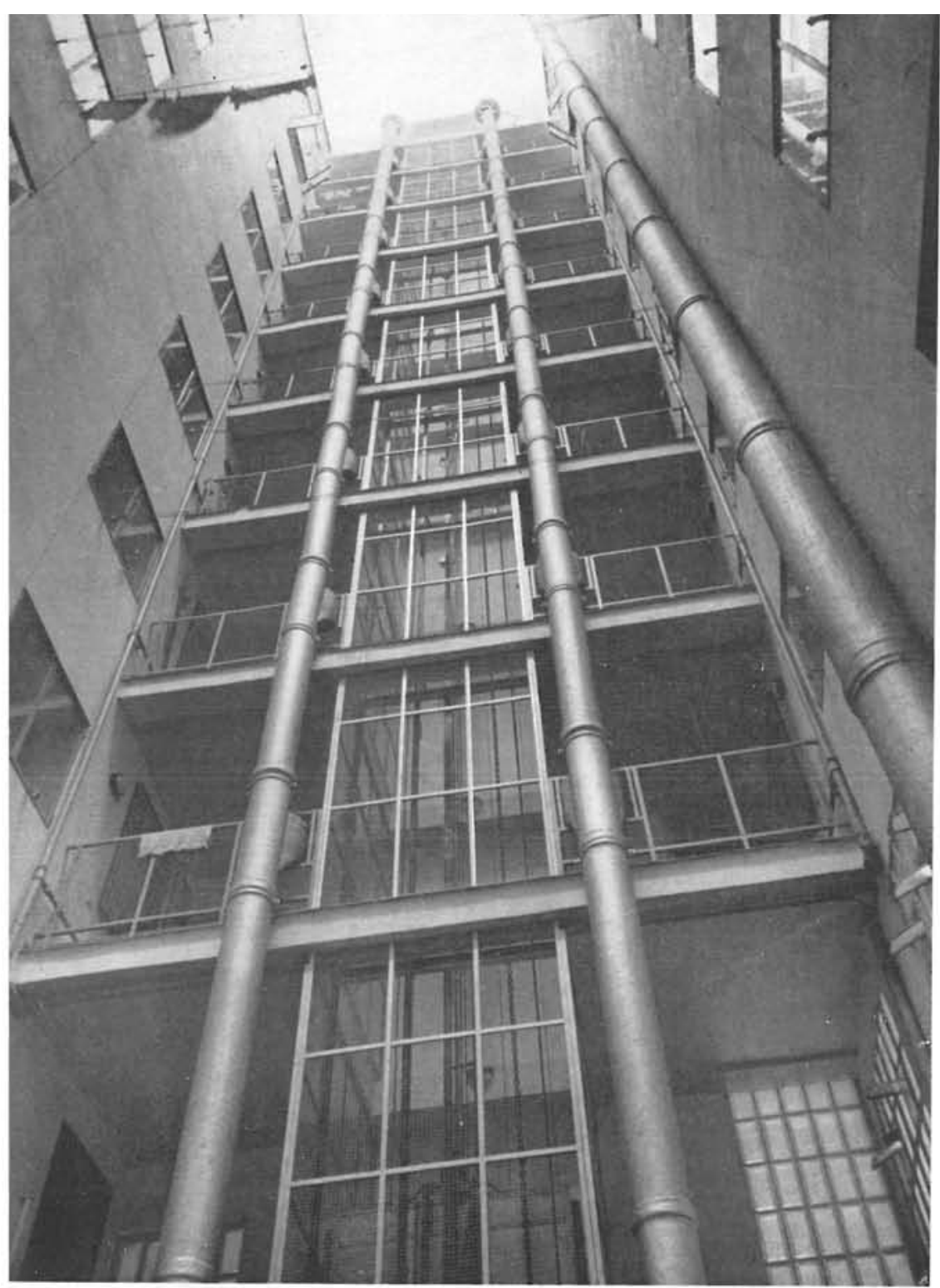

\section{patio $y$ escaleras}

Desde los primeros trazos del proyecto dominó la intención de realizar una arquitectura típica del uso a que iba a dársele: Viviendas. Una arquitectura sin alardes, tranquila, pero de calidad.

El programa es el típico de tres dormitorios, estar-comedor y zona de servicio, desarrollado en una superficie de $147 \mathrm{~m}^{2}$

En los apartamentos se estudia una solución amplia a base de dos dormitorios, estar-comedor, aseo y cocina, con un total de $71 \mathrm{~m}^{2}$.

En planta baja, locales comerciales.

El cerramiento exterior se realiza a base de carpintería metálica y acabados de piedra, buscando una compensación de zonas de luz y según las exigencias de la planta.
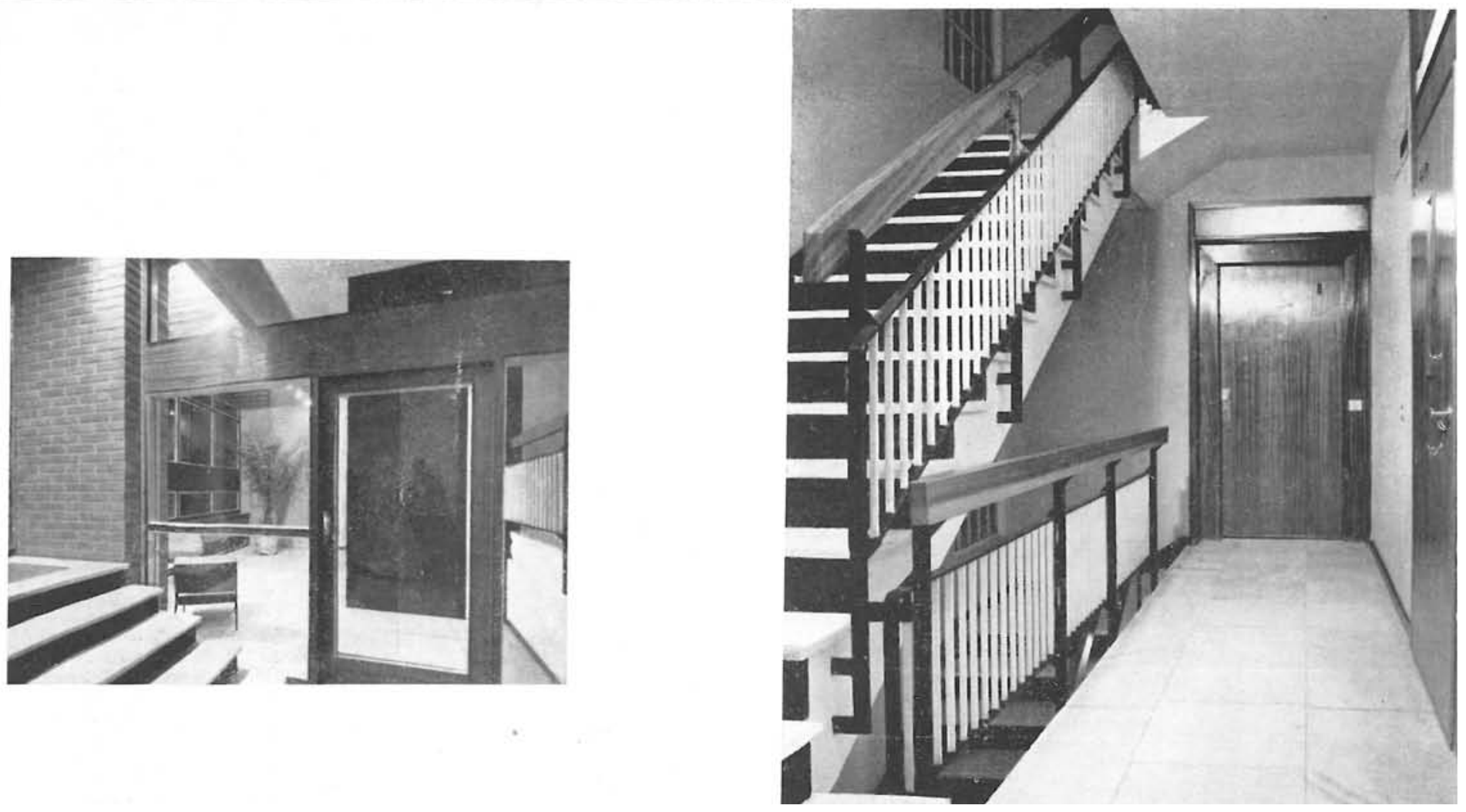


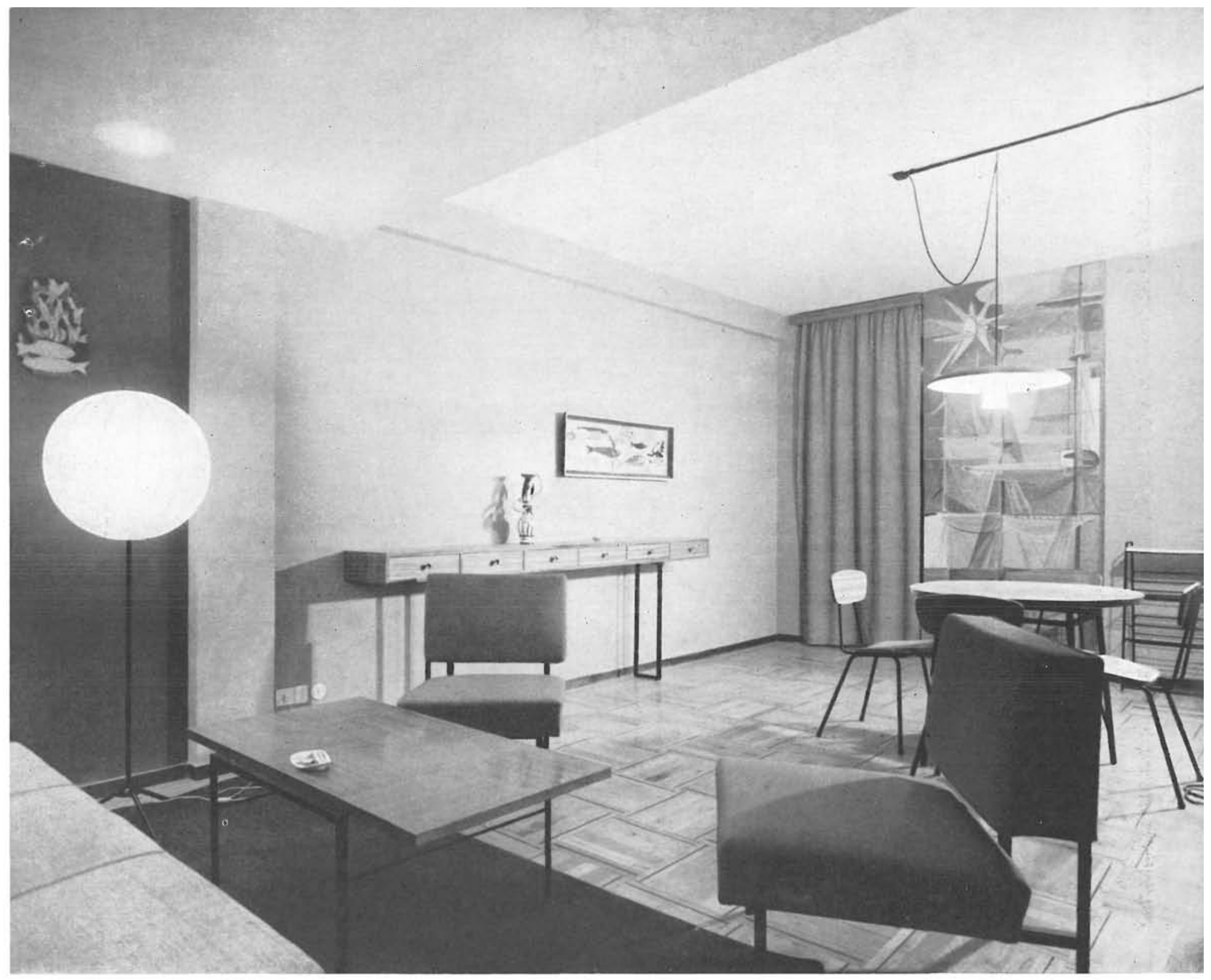

\section{interiores}

El volumen del conjunto se reduce a un paralelepípedo recto-rectangular cubierto por una placa de hormigón de línea quebrada protegida con impermeabilizante bituminoso y acabado de gravilla fina.

El empleo lógico de unos materiales, una distribución sincera en planta, y una intención de resolver sensatamente todos los problemas que surgen en este tipo de edificaciones, han dado al edificio la categoría que le podía corresponder.

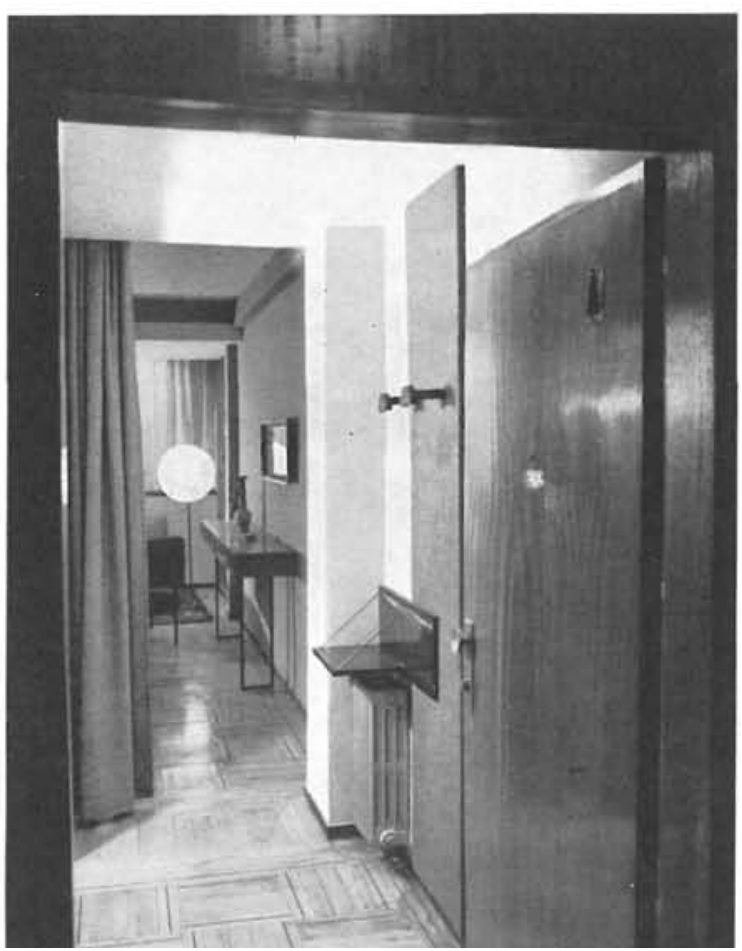




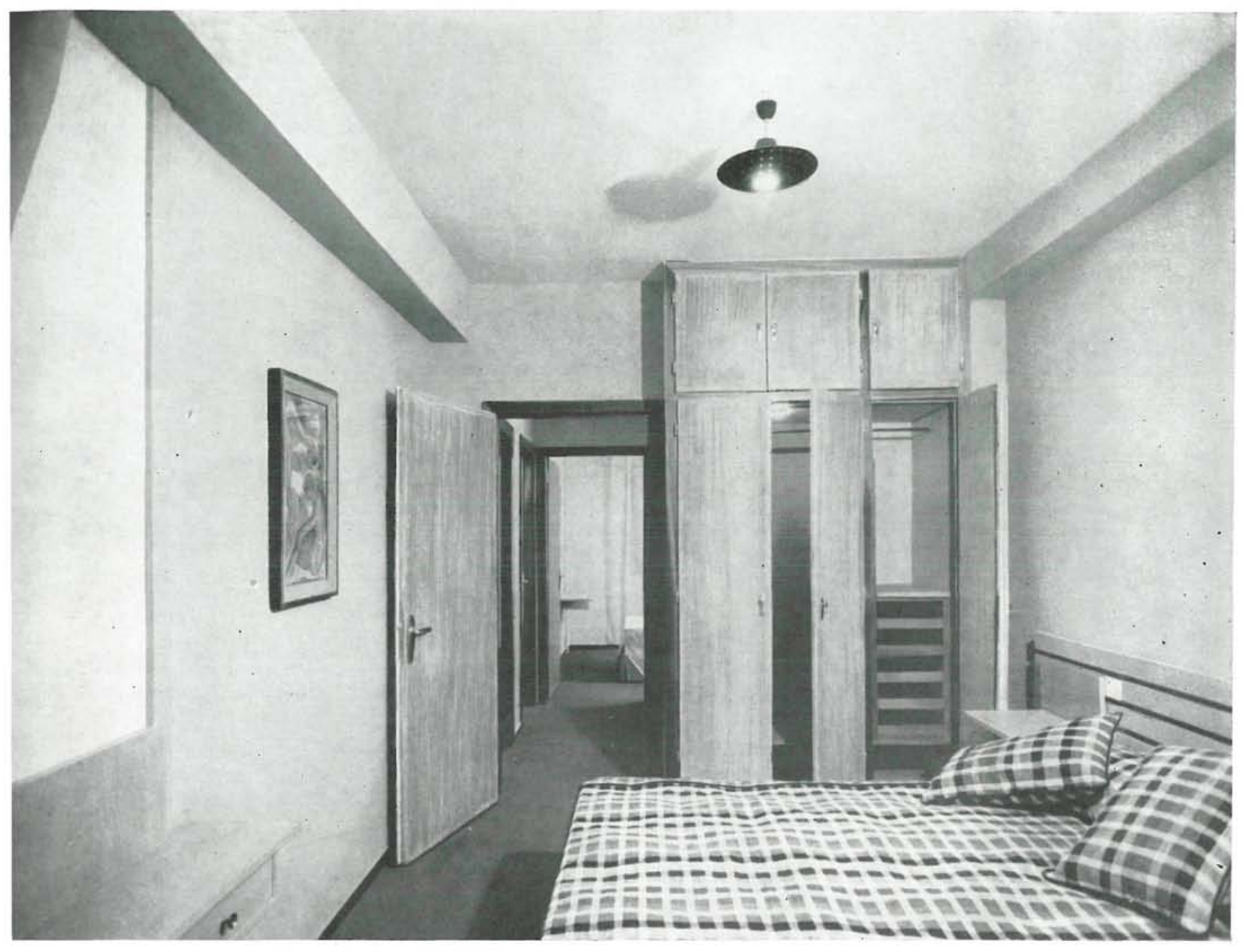

\section{interiores}

En el portal, un pirograbado sobre tablero de castaño decolorado, realizado por Arcadio Blasco, pone una nota alegre y atractiva.

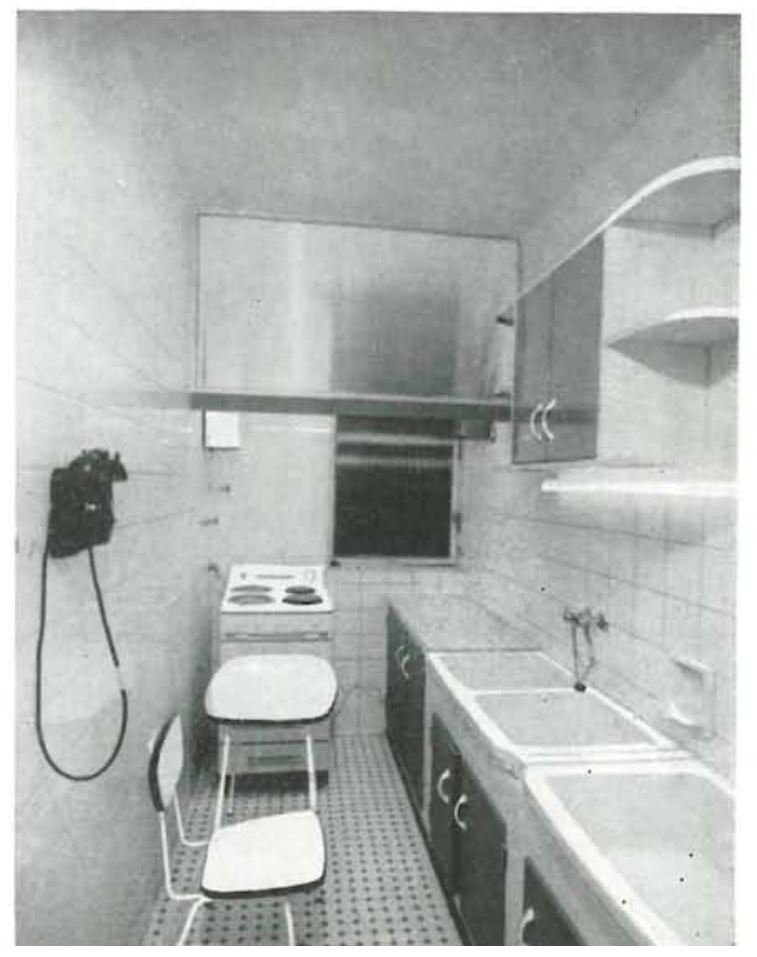

